\title{
O JORNAL COMO O VEÍCULO NO PROCESSO DE MOBILIZAÇÃO E ORGANIZAÇÃO DE GRUPOS COMUNITÁRIOS
}

\author{
Maria Dalva Santos Alves * \\ Zunele Marja de Vasconcelos Varela **
}

RESUMO -Grupos foram mobilizados durante as atividades de saúde por meio de jornal e rádio. $\mathrm{O}$ alvo da atividade foi contribuir para ajudar a população a decidir sobre os problemas de saúde e contribuir com a comunidade na mobilização e organização do processo.

\begin{abstract}
Peoples were mobilized during an activity through newspaper and radio. The aim of the activity was to contribute to help the population to decide about its health prpblems, to contribute to community mobilization and organization process.
\end{abstract}

\section{INTRODUÇÃO}

O Departamento de Enfermagem/UFC, vem desenvolvendo intensa atividade no campo da extensão desde início de seu funcionamento.

Essas experiências têm sido ef etivadas, tanto na periferia da capital, como em cidades interioranas e, até bem pouco tempo, no "campus" avançado da UFC, (enquanto foi mantido), no Xapuri, localidade do Território do Rio Branco.

Observando a atuação de docentes e discentes, temos percebido diferentes formas empregadas para reunir pessoas e se fazerem aceitos pela comunidade; temos acompanhado outros grupos de profissionais da área da saúde. Em todos evidencia-se a relação interpessoal caracterizada pelo que provê assistência na doença e aquele que recebe $o$ benefício (o doente).

PAULO FREIRE ao tratar das relações entre profissionais e usuários de serviços em trabalhos comunitários, discute os conceitos de basismo e elitismo, tendências prejudiciais e que, às vezes, passam despercebidos dos que os exibem, no afã de envolverem-se a ação.

Com relação ao elitismo, tem sido comum sua prevalência, sempre que órgãos públicos decidem treinar pessoal de níveis elementar e médio, para atuarem na assistência primária de saúde. Jovens são escolhidos da própria comunidade e levados para as salas de treinamento onde inciam o processo de assimilação de conhecimento sobre procedimentos e técnicas, sobre doenças, como cuidar dos doentes, como evitar doenças. Ao final do treinamento, se sentem, naturalmente pessoas mais importantes do que os seus iguais ao grupo que os gerou.

Outro fato que é do conhecimento de quantos se envolvem com a ação comunitária é a emergência de situações que fogem ao controle de quem está assumindo o papel de agente motivador da comunidade.

Sobre isso, um fato ilustrativo é o referente aquele membro de um grupo que, num determinado momento, inicia o processo de polarização em torno de si, criando uma relação de domininação e de medo, dificultando a ação do agente motivador e agindo sistematicamente na intenção de permanecer sozinho. Ele havia sido uma daquelas pessoas identificadas como tendo características de liderança; assumira no grupo, papéis importantes legitimados por todos. Essa posição o tornou conhecido como representante do grupo junto a instituições, aos poucos, foi-lhe conferindo poder sobre os demais. Com o passar do tempo,

* Professora Assistente do Departamento de Enfermagem/UFC especialista em Saúde Pública.

** Professora Adjunta do Departamento de Enfermagem/UFC-mestre em Saúde Comunitária. 
transformou-se em principal obstáculo ao desenvolvimento do grupo e à ação daqueles que ajudaram-no a projetar-se e que tentavam iniciar um processo de desenvolvimento comunitário.

Outro exemplo é o daquele universitário que, desejando iniciar-se num projeto de extensão, vestiu uma bata branca, colocou um estetoscópio no pescoço e saiu a passear por um bairro de famílias carentes. Logo se viu cercado por pessoas de diferentes idades que lhe pediam remédio e se queixavam de toda espécie de doenças. A partir de então, conseguiu introduzir na comunidade e mobilizou as famílias. Infelizmente não conseguiu livrar-se da primeira impressão causada nos que o viram naquele primeiro dia de chegada ao bairro.

Em visita de observação do PAPPS de Campinas - Programa de Apoio Pedagógico aos Profissionais de Saúde, tomamos conhecimento da estratégia utilizada por um grupo de profissionais como usuários dos serviços do Posto de Saúde onde atuavam.

No primeiro momento deflagrava-se uma discussão no sentido de se indentificar os problemas de cada um; enquanto conversavam, um dos participantes (funcionário do Posto), ia tradizindo para desenho em folhas de papel tipo ofício, aquilo que era relatado, de forma que, ao final ele compôs com uma série de lâminas, expressando diferentes problemas sócio-sanitários. Posteriormente esses desenhos eram xerografados de forma a que, numa próxima reunião, se pudesse colocar uma mesa a pilha de papéis desenhados. Cada participante era convidado a selecionar algumas lãminas, e, a partir delas, formar uma história, a sua própria história, de vida. Após isso, cada uma narraria a história usando a lâminas para ilustrar.

Numa próxima etapa cada grupo de lâminas que constituía uma história pessoal, era transformada em álbum seriado o qual seria exibido pela equipe numa reunião subseqüente.

Cada sessão tinha por centro de interesse esses mesmos problemas. A diferença residia no fato de que as pessoas eram levadas a compreender a relação de causa-efeito entre problemas e situação sócio-política do país e, portanto de todos os brasileiros, não somente dos que estavam ali presentes. Assim, o grupo partia da ótica individualista, personalista, do pensamento ingênuo evoluindo, em cada etapa, para compreensão de que na raiz de todos os problemas individuais estão comuns a todos. 0 grupo evoluia para uma visão sociológica dos fatos.

Em todas essas, e em outras tentativas de ação comunitária do nosso conhecimento, sem eliminar os míritos nelas envolvidos, existem as desvantagens de baixa cobertura populacional atingida por sessão, do papel passivo de receptor assumido pelo grupo. Há uma desvantagem maior - a de relacionar os grupos mobilizados à pessoa ou instituição que iniciou o processo.

Essa problemática se torna mais preocupante quando nos deparamos com o processo ensino-aprendizagem realizado nos campos de prática de enfermagem de saúde pública nos moldes convencionais.

Uma de nós tem insistido na necessidade de colocar o aluno na comunidade, junto às famílias, aos grupos de visinhança, às associações de bairro tentando assumir papéis que legitimem sua presença entre eles. 0 que seria diferente do que vê comumente, em que o aluno é colocado numa unidade sanitária ou escola e, dali, parte para realizar ações, procedimentos ou outro termo que se queira usar, em visitas a domicilios escolas ou creches, por exemplo.

Atualmente, 0 aluno em prática de enfermagem de saúde pública ou disciplinas afins, não adquire a maturidade esperada num futuro profissional generalista. Ele não consegue visualizar que a problemática não é inerente à prática no campo da saúde pública mas tem causas mais profundas relacionadas ao contexto sócio-político e econômico do país. Ao invés, deixa-se empolgar pela aparência de trabalho organizado e bem estruturado, de resultados concretos e imediatos que apresenta o hospital. Uma empolgação ingênua uma vez que se sabe que por trás dessa aparência os problemas são os mesmos. Nessa linha de raciocínio, o aluno passa a valorizar, quase que exclusivamente, as esperiências vivenciadas no contexto hospitalar, adquirindo um comportamento assistencialista, imediatista, individualista. Esse comportamento é altamente prejudicial ao que se espera do generalista dentro do que é preconizado na política de extensão de cobertura.

0 que se pretende com esse projeto ou outros semelhantes é diversificar a prática de enfermagem de saúde pública, procurando dar-lhe um enfoque mais comunitário que institucional, procurando contemplar o papel ampliado do profissional nas funções e assessoria, consultoria, extensão, mediação junto à familia, grupos comunidades e instituições (ARCHER, 1977).

\section{MOBILIZAÇÃO E ORGANIZAC̣ÃO COMUNI- TÁRIA}

A mobilização e organização comunitária se deu a partir de programa de rádio e encartes em jornal - aspectos metodológicos e estruturais.

\subsection{A Universidade aberta - o povo}

A experiência ora narrada foi possibilitada através da Universidade Aberta do Jornal O Povo. Funciona com as Universidade Federal e Estadual do CEARÁ e Brasília.

Ao ser projetada a Universidade Aberta propunha um sistema de assistência ao aluno. Esse sistema compôe-se de quatro subsistemas - o serviço de tutoria, os círculos de estudos dirigidos, o "tira-dúvidas" e a correspondência pelo correio.

A tutoria compreende uma assistência direta a grupos formados na comunidade que solicitam a assitên- 
cia dos instrutores do curso quando dificuldades estão prejudicando a aprendizagem. Através de seu coordenador os círculos de estudos mantêm contato permanente com a Universidade Aberta. Quando por algum motivo não se faz presente o tutor aos círculos de estudos o jornal propicia espaço para que se publiquem as dúvidas com os respectivos esclarecimetos.

\subsection{Projeto informação e auto-gestão em saúde.}

Os Ministros de Saúde da América Latina e Caribe assumiram na III Reunião de Ministros de Saúde das Américas o compromisso de proporcionar serviços básicos de saúde às populações carentes através da estratégia de extensão de cobertura. Esta decisão veio em resposta ao diagnóstico realizado, quando verificadas as condições em que viviam essas populações e a falência dos recursos convencionais utilizados pelos países isolamento.

A nova estratégia entende que a atenção primária de saúde, regionalizada e hierarquisada, apoiada por decisão governamental cobrirá as necessidades básicas de saúde da população até o ano 2.000.

Considerando que as populações carentes o são também por falta de informações sobre os aspectos básicos de saúde; que a informação pode acionar o processo interno de tomada de decisão; que esta tomada de decisão pode ser estimulada e implementada por uma ação organizada mobilizadora; que os meios de comunicação de massa podem exercer relevante papel nesse processo, segue-se o Projeto "Saúde: Informação e auto gestão".

0 projeto pretende expressar-se como um processo de divulgação de informações básicas de saúde. Saúde compreendida no contexto amplo e não só como "o completo bem estar físico, mental e social e não somente ausência de doenças".

Este conceito será operacionalizado através de mensagens radiofõnicas e encartes de jornal que, num segundo momento, poderão gerar uma resposta mais objetiva às demanda de informações sobre problemas reais da clientela.

O projeto orientar-se-á pelos seguintes princípios: - A comunidade tem capacidade de auto gerir-se; - A comunidade tem condições de identificar seus problemas e necessidades;

- A comunidade desconhece a relação causa-ef eito de seus problemas e carências;

- A comunidade necessita de informação sobre as formas de encaminhamento para solução de seus problemas e dos problemas do meio;

- A comunidade necessita assumir sua contribuição na redução de agentes agressores do meio;

- A comunidades necessita conhecer a parcela de contribuição das instituições comunitárias e governamentais de saúde na resolução dos problemas sócio-sanitários;

- As famílias devem exercer seu direito de determi- nar o número de filhos e o espaço intergestacional. - A mulher necessita conhecer seu corpo em todos os seus aspectos, especialmente o que se refere à reprodução humana;

- O homem necessita compreender o conceito de paternidade responsável.

A metodologia e estratégia foram trabalhadas de forma a envolver discentes, docentes, convidados, equipe técnica do jornal e rádio. Dentre os convidados estiveram profissionais e agentes de saúde.

A produção radiofõnica e a produção de matéria para encartes do jornal, versaram sobre temas de interesse no campo da saúde materno-infantil no sentido mais amplo - mulher em todas as fases de crescimento e desenvolvimento humano, abrangendo, ainda os papéis assumidos de mãe e cõnjuje; criança desde a concepção até a adolescência contemplando suas necessidades bio-psico-sociais.

0 trabalho será realizado em fases:

- Fase preliminar para diagnóstico de necessidades em informação sobre saúde. Será implementada a partir do incentivo ao envio de perguntas para o programa. - Mensagens sobre a forma de - Slogans de utilidade pública.

- textos

- Cursos para - gestantes, mães de primeiro filho, babás, adolescentes, socorro de urgência e prevenção de acidentes; aspectos sobre saneamento básico e aspectos sobre higiene mental.

A estrutura organizacional do projeto foi idealizado de forma a envolver docentes das áreas de saúde pública e materno-infantil que assumiriam temas de sua competência colocando-à disposição caso fossem solicitadas para compor o grupo de tutoria. Definiu-se uma coordenação técnico-administrativa e uma coordenação de produção. Os discentes participantes seriam selecionados dos últimos semestres para comporem, juntamente com os docentes, o grupo de tutoria.

Por se tratar de uma experiência nova para as professoras, consideramos que o desafio foi absorvido por todas com determinação e vontade de contribuir efetivamente com a comunidade.

Os assuntos a serem abordados já constavam do projeto inicial, entretanto foram feitas sub-divisões para facilitar 0 encadeamento dos mesmos.

Toda a produção de material surgiu a partir de referências bibliográficas e experiências do professor que se orientou pelas linhas básicas do projeto.

Ao mesmo tempo em que se prepara material para o jornal, era elaborado roteiro para as aulas pelo rádio.

As gravações foram feitas em "studio" sendo trabalhadas com recursos radiofõnicos por uma jornalista também professora da UFC.

Após recolhimento do material produzido providenciava-se a revisão de português, no linguajar adequado e encaminhava-se à datilógrafa. Após isso, nova revisão era feita para entrega do fascículo com montagem das figuras, fotos, quadros, tabelas. 
O Curso "Em defesa da Saúde", parte do projeto Informação e auto-gestão em saúde, chegou às comunidades do Ceará (capital e interior) e do Rio Grande do Norte em 13 fascículos semanais e 26 aulas duas vezes por semana, atingindo através de inscrições, 763 pessoas. Tem-se conhecimento de um grande número que acompanhava o jornal sem sentir a necessidade de formalizar sua participação.

Ao final, os participantes que cumprirem os objetivos propostos receberão certificado de conclusão do curso.

\section{RESULTADOS E COMENTÁRIOS}

\subsection{Caracterização da clientela.}

Setecentos e sessenta e três pessoas, de diferentes grupos etários e profissões, inscreveram-se no Curso "Ém Defesa da Saúde" parte do projeto "Informação e auto-gestão em saúde.

A grande maioria (80\%) são procedentes do Estado do Ceará; os demais do Rjo Grande do Norte. O Interior do Estado do Ceará contribuiu com 154 inscritos atingindo um quarto de todos os inscritos no referido Estado.

Quanto ao sexo, 464 são mulheres e 299 homens prepoderando a faixa etária entre 20 e 30 anos. As idades variaram entre menor de 15 anos e 31 e mais anos.

No que se refere à escolaridade 138 afirmavam ter o $1^{\circ}$. grau, 243 têm o $2^{\circ}$. grau, 199 têm o $3^{\circ}$. grau; 183 nada mencionaram.

No que tange à ocupação, 90 exercem profissão de nível superior; 239 são estudantes (61 de nível superior); 243 estão no grupo dos que exercem atividades de nível elementar ou médio. Em torno de 2 centenas nada mencionaram.

Sabe-se de pessoas que não se preocuparam em efetivar sua inscrição. Dado isso, é de se esperar que seja muito mais alto o número de pessoas atingidas pelo curso.

\subsection{Opinião dos professores que participaram do Curso.}

Todos os docentes participantes foram unãnimes em expressar na avaliação realizada por ocasião do término do curso, (na presença da equipe do jornal e rádio), quanto por escrito, que a experiência foi válida e enriquecedora; um desafio e um novo aprendizado.

Seguem trechos dos depoimentos de docentes.

"A falta do grupo de pessoas presentes no momento da gravação faz com que tenhamos de falar para o grupo e não com o grupo, isso, no início me deixava pouco à vontade durante as aulas".

"foi um momento excelente para maior integração entre os professores de reflexão em torno de diferentes questões"'...
"Vivência de um sentimento de realização ao ler o fascículo de autoria própria".

Todas reagiram ao tomar conhecimento de que as aulas seriam gravadas pelas próprias autoras. À proporção que se sucediam as gravações, a experiência ia se tornando familiar e gratificante.

Foram mencionadas as referências elogiosas que o grupo recebeu de profissionais de outras áreas, de amigos e clientes.

"Muitas pessoas me identificaram no fascículo e me telefonaram. Recebi elogios publicados em dois jornais locais pelo trabalho".

Foi lembrado o caráter publicitário de que se revestiu a participação de um grupo de enfermeiros em programas de rádio e jornal, tanto entre os que conviveram na produção e realização dos programas, quanto em relação ao grande público.

Vale salientar que foi a primeira experiência realizada na área de saúde em Fortaleza:

Outro aspecto evidenciado foi a concretização do ideal de ação multiprofissional, interdisciplinar e interinstitucional. Além dos que integravam a equipe técnica do rádio e jornal foram convidadas enfermeiras de ensino de outra universidade e, de serviços de saúde, bem como assistente social e agente de saúde.

Houve preocupação em conhecer a repercussão do curso nas comunidades do Rio de Grande do Norte. Foram contactados profissionais de diferentes áreas de atuação e agentes de saúde da Fundação SESP, Secretaria de Saúde e de Educação do Município, Fundação de Saúde, Associação Médica vigário local.

As opiniões colhidas e gravadas em fita cassete nos deixaram entrever motivação em participar e divulgar. Dentre manif estações concretas vale salientar a intenção de formação de grupos de jovens pelo vigário de uma das comunidades para operacionalizar as sugestões apresentadas no curso; ressalte-se, também, a intenção de envolver a rede de ensino, especialmente, no que refere ao ensino de programas de saúde.

\section{CONCLUSÕES E SUGESTÕES}

A experiência do contato com o grande público, através de meios de comunicação de massa, abre um novo espaço para atuação no campo da enfermagem. Isso, tanto em relação ao campo publicitário, vendendo uma imagem positiva da profissão, como também, no que tange à prestação de serviços nas funções de assessoria, consultoria, mediação e no campo da extensão aplicando o princípio da cobertura populacional. O contato íntimo com os meios de comunicação de massa desperta o profissional para o compromisso social através de uma nova linguagem com as conseqüentes implicações naturais do compromisso assumido publicamente.

Foi expressiva a receptividade ao curso evidenciada através das 763 inscrições individuais e da solicita- 
ção, por carta do material produzido, por entidades públicas, privadas e filantrópicas, de todo país. A demanda pelo material estimulou-nos a enviá-lo para todas as entidades públicas ligadas à promoção da saúde coletiva.

Avaliação feitas a partir do contato com representantes de comunidades expressaram consenso quanto à validade do empreendimento, sua oportunidade no momento da constituinte e reforma sanitária; reforçaram a necessidade de que não haja solução de continuidade.

Avaliações feitas, intimamente, reunindo os que produziram e os que editaram as aulas, resultou em comentários elogiosos quanto à forma como o grupo se organizou e atuou além de mensão elogiosa ao material produzido.

Foi sugerido que se diversifique a forma de divugação prévia de experiência semelhantes e que os contatos com as comunidades aconteçam em dois momentos antese a o final de todo o processo, e que as comunidades tomem conhecimento prévio dos serviços oferecidos pela Universidade Aberta, de tal modo, a se sentirem motivados a solicitatutoria.

\section{PERSPECTIVAS EM ETAPAS POSTERIORES}

Pretende-se levar a ef eito a avaliação do impacto atingido através de questionário que será enviado aos inscritos na forma que segue

1. Você tomou conhecimento de acontecimentos ligados ao curso "Em Defesa da Saúde"? Conte para nós. Grupos que se tenham formado. Idéias que pessoas ou grupos tenham posto em prática em escolinhas, bair- ro, etc... 2. Você conhece algum fato que tenha ocorrido porque alguém leu, ou escutou pelo rádio, as aulas do Curso! - Soluções de problemas nas famílias, no bairro, etc... - Encontro entre grupos ou associações . 3. Você conhece pessoas líderes no seu bairro, que tenham feito curso e que possam nos escrever contando o que acharam do curso? - Vigários ou ministros de outras religiões, prof essores, vereadores, funcionários do posto de saúde ou hospital, parteiras. 4. Você sabe dizer se alguém mudou, de alguma forma, a partir do que leu ou ouviu no jornal e no rádio? - Conte para nós as dificuldades que você porventura tenha sentido durante o Curso. 6. Envie sugestões para outros cursos ou para aperfeiçoamento deste.

Pretende-se utilizar essa experiência da mobilização comunitária com o propósito de oportunizar a organização de grupos de reflexão em saúde no sentido amplo da palavra sob a assessoria de docentes de enfermagem - área de saúde pública, organizar novos contextos para a prática de enfermagem de saúde pública centrada, não na rede de serviços de saúde, mas na família e grupos da vizinhança; diversificar as experiências de aprendizagem levando o aluno a trabalhar com o enfoque sociológico e político, estimular a manifestação das funções de assessoria, consultoria, mediação e extensão no campo da enfermagem de saúde pública.

\section{REFERÊNCIAS BIBLIOGRÁFICAS}

1 ARCHER, Sarah Ellen \& FLESHMAN, Ruth. Enfermeria de salud comunitaria. Colômbia, OPAS/OMS, 1977. p. 1-11

2. FREIRE, Paulo. Conversando com o povo. mimeogr.

3.O Povo Universidade Aberta: a maior invenção do século XX. Jornal O Povo, Fortaleza. 